\title{
The effect of the acute phase response on routine laboratory markers of folate and vitamin B12 status
}

Jayne P Parkes ${ }^{1}$, Lorna Wood ${ }^{1}$, Andrew J Chadburn ${ }^{1}$, Elizabeth Garman ${ }^{1}$, Raad Abbas $^{2}$, Anu Modupe ${ }^{1}$, Simon J Whitehead ${ }^{1}$, Clare Ford ${ }^{1}$, Osmond L Thomas ${ }^{2}$, Sanjiv Chugh ${ }^{2}$, Shreeram Deshpande ${ }^{2}$, Rousseau Gama ${ }^{1,3}$

${ }^{1}$ Blood Sciences and ${ }^{2}$ Orthopaedics, The Royal Wolverhampton NHS Trust, Wolverhampton, UK and ${ }^{3}$ Research Institute, Healthcare Sciences, Wolverhampton University, Wolverhampton, UK.

\section{Correspondence to:}

Jayne Parkes

e-mail: jayne.parkes@nhs.net

Tel: $+44(0) 1902695295$

Fax: +44 (0) 1902695640

\section{Declaration of conflicting interests}

We have no conflicts of interest with respect to the research, authorship, and/or publication of this article.

\section{Funding}

This research received no grant from any funding agency in the public, commercial or not-for-profit sectors. The authors received no financial support for the research, authorship, and/or publication of this article. 


\author{
Ethical approval \\ Granted by the National Research Ethics Service (NRES Committee South \\ Central -Hampshire B; study code 14/SC/1396).
}

\title{
Guarantor
}

$R G$.

\section{Contributorship}

JPP researched the literature, supervised analyses, analysed MMA samples, analysed the data and wrote the first draft. LW analysed other haematinic analytes. AJC supervised sample processing and storage. EG designed the study, wrote the protocol and submitted the study for ethical approval. RAand AM helped supervise the study, recruited patients, collected demographic data, took consent and collected samples. SJW developed and validated the MMA assay. $C F$ and $R G$ helped design the study and write the research protocol. OLT, SC, SD, CF and RG contributed to the data. RGonceived the study. All authors reviewed and edited the manuscript and approved the final version of the manuscript.

\section{Acknowledgments:}

We thank Mr Pemmaraju and Mr Hart for allowing us to recruit patients under their clinical care.

\section{Keywords:}

Acute phase response (APR), Total B12, Active B12 (Holotranscobalamin), Methyl Malonic Acid, Serum Folate, Ferritin, Iron, Transferrin, Transferrin Saturation, TIBC (Total Iron Binding Capacity), Haemoglobin. 


\section{Letter}

The effect of the acute phase response (APR) on laboratory biomarkers of iron status is well known, and typically show increased serum ferritin and decreased serum iron, transferrin, total iron binding capacity (TIBC) and transferrin saturation $[1,2]$. In contrast, there are limited and conflicting data on the effect of the APR on serum biomarkers of vitamin B12 and folate. Serum total B12 has been reported asinaffected by surgery [3] but the high total serum B12 seen in malignancies, inflammatory diseases and the critically ill has been attributed by most [4] but not all [5] asbeing due to inflammation. Similarly, serum folate has been reported asreduced [6] or unaffected [3] by surgery. There are no prospective data on the effect of the APR on serum active B12 or methylmalonic acid (MMA). We, therefore, prospectively evaluated the effect of the APR, aprovoked by elective orthopaedic surgery, on laboratory biomarkers of iron, vitamin B12 and folate status to establish their validity in acute illness.

Thirty patients (14 male) aged 70.0 (9.4) years gave informed written consent to participate in this study approved by the National Research Ethics Service. Exclusion criteria included patients who received blood transfusion within three months, known to have haematological and liver disorders and on medication known to affect vitamin B12 and folate. Blood samples were collected on the morning of and 48 hours after surgery. $\mathrm{Hb}$ was measured soon after collection. Serum was separated within two hours of collection, aliquoted and frozen at $-80^{\circ} \mathrm{C}$ until analysed in single batches.

$\mathrm{Hb}$ was measured on the Sysmex $\mathrm{XN}-10{ }^{\circledR}$ (Sysmex Corporation, Kobe, Japan). CRP, transferrin and iron were measured on the Abbott ARCHITECT C16000 analyser and total B12, active B12, folate and ferritin on the Abbott 
ARCHITECT i2000sr analyser using methods and reagents supplied by Abbott diagnostics (Abbott Diagnostics, Abbott Park, IL, USA). MMA was measured by liquid chromatography-tandem mass spectrometry using anAB Sciex QTrap 6500 analyser (Sciex, Framingham, MA, USA) connected to a Shimadzu LC20AD XR HPLC system (Shimadzu Corporation, Kyoto, Japan) based on a previously described method [7]. TIBC (25.1 xTransferrin) and transferrin saturation (Iron/TIBC $\times 100$ ) were calculated.

CRP and total B12 data were non-parametric but were normally distributed following logarithmic transformation. Other data were parametric. Student's ttest and Pearson's linear correlation, therefore, assessed the significance of differences and association respectively between raw and logarithmically transformed parametric data. Data (including pre-transformed raw CRP and total B12 data) are expressed as means with standard deviation in parentheses.

Following surgery, CRP and ferritin significantly increased; $H b$, iron, transferrin, TIBC, transferrin saturation and folate significantly decreased; whereas total $B 12$, active $B 12$ and $M M A$ remained unchanged (Table). Logarithmic CRP correlated positively with ferritin $(r=0.488, p=<0.0001)$ and negatively with iron $(r=-0.864, p=<0.0001)$, transferrin $(r=-0.567, p=<0.0001), \operatorname{TIBC}(r=-0.568$, $p=<0.0001)$, transferrin saturation $(r=-0.800, p=<0.0001)$, haemoglobin $(r=-0.506$, $p=<0.0001)$ and folate $(r=-0.279, p=0.0307)$. There were no correlations between logarithmic CRP and logarithmic total B12 ( $r=-0.124, p=0.3451)$, active B12 ( $r=-$ $0.065, p=0.6241)$ or $M M A(r=0.104, p=0.4301)$. 
Table. Mean (SD) laboratory data in 30 patients before and 48 hours after elective knee or hip surgery

\begin{tabular}{|c|c|c|c|}
\hline Analyte & Before surgery & After surgery & p Value \\
\hline $\begin{array}{l}{ }^{\star} C R P \\
(m g / L)\end{array}$ & $\begin{array}{l}4.76 \\
(7.59) \\
\end{array}$ & $\begin{array}{l}179.70 \\
(61.89) \\
\end{array}$ & $<0.0001$ \\
\hline $\begin{array}{l}{ }^{*} \text { Total B12 } \\
(\mathrm{pg} / \mathrm{ml})\end{array}$ & $\begin{array}{l}381.8 \\
(154.2)\end{array}$ & $\begin{array}{l}374.6 \\
(215.0)\end{array}$ & 0.8151 \\
\hline $\begin{array}{l}\text { Active B12 } \\
\text { (pmol/L) }\end{array}$ & $\begin{array}{l}104.8 \\
(49.1)\end{array}$ & $\begin{array}{l}100.6 \\
(59.1)\end{array}$ & 0.6257 \\
\hline $\begin{array}{l}\text { MMA } \\
(\mathrm{nmol} / \mathrm{L})\end{array}$ & $\begin{array}{l}185.7 \\
(115.7)\end{array}$ & $\begin{array}{l}207.2 \\
(89.5) \\
\end{array}$ & 0.2865 \\
\hline $\begin{array}{l}\text { Folate } \\
(\mathrm{ng} / \mathrm{ml})\end{array}$ & $\begin{array}{l}7.34 \\
(4.27) \\
\end{array}$ & $\begin{array}{l}5.74 \\
(2.95) \\
\end{array}$ & 0.0017 \\
\hline $\begin{array}{l}\text { Ferritin } \\
(\mathrm{ng} / \mathrm{ml})\end{array}$ & $\begin{array}{l}102.8 \\
(78.4)\end{array}$ & $\begin{array}{l}233.0 \\
(138.1)\end{array}$ & $<0.0001$ \\
\hline $\begin{array}{l}\text { Iron } \\
\text { (umol/L) }\end{array}$ & $\begin{array}{l}15.75 \\
(5.38)\end{array}$ & $\begin{array}{l}4.58 \\
(1.17)\end{array}$ & $<0.0001$ \\
\hline $\begin{array}{l}\text { Transferrin } \\
(g / L)\end{array}$ & $\begin{array}{l}2.608 \\
(0.396)\end{array}$ & $\begin{array}{l}2.094 \\
(0.333)\end{array}$ & $<0.0001$ \\
\hline $\begin{array}{l}\text { TIBC } \\
\text { (umol/L) }\end{array}$ & $\begin{array}{l}65.5 \\
(9.9)\end{array}$ & $\begin{array}{l}52.6 \\
(8.4)\end{array}$ & $<0.0001$ \\
\hline $\begin{array}{l}\text { Transferrin sat } \\
(\%)\end{array}$ & $\begin{array}{l}24.8 \\
(9.4)\end{array}$ & $\begin{array}{l}8.8 \\
(2.2)\end{array}$ & $<0.0001$ \\
\hline $\begin{array}{l}\text { Haemoglobin } \\
(\mathrm{g} / \mathrm{L})\end{array}$ & $\begin{array}{l}134.0 \\
(16.4)\end{array}$ & $\begin{array}{l}111.4 \\
(17.6)\end{array}$ & $<0.0001$ \\
\hline
\end{tabular}

*Pre-transformed data shown but logarithmic data analysed

The 37-fold increase in CRP confirmed anAPR. The well-established effects on laboratory biomarkers of iron status were also confirmed; namely increased serum ferritin and decreased serum iron, TIBC, transferrin and transferrin saturation values $[1,2]$. Alternative biomarkers and diagnostic strategies have, therefore, been advocated in the laboratory assessment of iron status in acute and chronic inflammatory conditions [1, 2]. 
Vitamin B12 in plasma is bound to haptocorrin as holohaptocorrin (80-94\%) or transcobalamin asholotranscobalamin (6-20\%) [8]. Only vitamin B12 bound to transcobalamin is available to the cells [8]. Total B12 assays measure holohaptocorrin and holotranscobalamin; whereas the active B12 assay measures only holotranscobalamin [8]. MMA is ofunctional biomarker for B12 deficiency as it increases in deficiency because cobalamin is required for the cofactors involved in its metabolism [8]. In this study, total B12, active B12, MMA and by implication holohaptocorrin and holotranscobalamin were unaffected by acute inflammation. The hypercobalaminaemia seen in malignancies and inflammatory diseases is therefore not due to acute inflammation apreviously speculated [4] and may be related to liver dysfunction rather than inflammation [5].

The decrease in serum folate following surgical insult is similar to a previous report [6] but differs from another reporting no change [3]. The mechanisms for this are unclear. Although pre-operative samples were fasting, it was unclear which post-operative samples were fasting or non-fasting. An increased number of non-fasting post-operative samples, however, would not explain the decreased serum folate since a post-prandial sample would be expected to have increased serum folate asthis would reflect recent dietary folate intake [9, 10]. Reduced post-operative nutrient intake was also unlikely since short-term fasting increases serum folate [11]. The negative correlation between CRP and serum folate in this study and previous report [12] also support serum folate being megative acute phase reactant. As postulated by Sorti et al, this may be due to increased folate utilisation to support increased glutathione production to combat oxidative stress [6]. We, however, cannot exclude the possibility that blood loss during surgery may have had anmpact on serum folate. 


\begin{abstract}
Our study has limitations. The a priori sample size was powered on changes in acute phase protein biomarkers, but the study group was relatively small and may have been under-powered for assessing changes in Vitamin B12 biomarkers and serum folate and therefore subject to type 1 and type ztatistical errors respectively. The effect on haematinic biomarkers was studied two days after elective surgery, and the longer term effect of an APR on haematinic biomarkers remains to be clarified. Although most unlikely, it is possible that the effect on haematinic markers by anAPR elicited by orthopaedic surgery reported in this study may not be applicable to APRs triggered by other inflammatory insults
\end{abstract}

In summary, we confirm the effects of the APR on biomarkers of iron status. We report that anAPR lowers serum folate but has no effect on biomarkers of vitamin B12 status. This indicates that routine laboratory biomarkers of iron and folate status may be unreliable in acute illness. The laboratory assessment of vitamin B12 status, however, is unaffected by acute illness. 


\section{References}

1. Northrop-Clewes CA. Interpreting indicators of iron status during an acute phase response tessons from malaria and human immunodeficiency virus. Ann Clin Biochem. 2008; 45:18-32.

2. Camaschella C. Iron-Deficiency Anemia. N Engl J Med 2015; 372:183243.

3. Foschi D, Rizzi A, Zighetti ML, Bissi M, Corsi F, Trabucchi E, Mezzetti M, Cattaneo $M$. Effects of surgical stress and nitrous oxide anaesthesia on peri-operative plasma levels of total homocysteine. Aandomised, controlled study in general surgery. Anaesthesia. 2001;56:676-9.

4. Andres $E$, Serraj K, Zhu J, Vermorken A J M. The pathophysiology of elevated vitamin B12 in clinical practice. Q J Med. 2013; 106:505-15.

5. Callaghan FM, Leishear K, Abhyankar S, Demner-Fushman D, MCDonald $C J$. High vitamin B12 levels are not associated with increased mortality risk for ICU patients after adjusting for liver function: a cohort study. ESPEN J. 2014 Apr 1:9(2):e76-e83.

6. Storti S, Cerillo AG, Rizza A, Giannelli I, Fontani G, Glauber M, Clerico A. Coronary artery bypass grafting surgery is associated with a marked reduction in serum homocysteine and folate levels in the early postoperative period. Eur J Cardiothorac Surg. 2004:26:682-6

7. Lakso HA, Appelblad P, Schneede J. Quantification of methylmalonic acid in human plasma with hydrophilic interaction liquid chromatography separation and mass spectrometric detection. Clin Chem. 2008;54:202835

8. Hunt A, Harrington D, Robinson S. Vitamin B12 deficiency. BMJ. 2014:349:g5226. doi: 10.1136/bmj.g5226

9. Sweeney MR, McPartlin J, Weir DG, Daly L, Scott JM. Postprandial serum folic acid response to multiple doses of folic acid in fortified bread. Br J Nutr. 2006:95:145-51.

10. Noy V, Baracaldo CM, Forero Y, Poveda E, Sánchez MR, Castro de Navarro $L$. Stability and effect of ingestion on the levels of folate in plasma. Biomedica. 2002:22:46-50.

11. Cahill E, McPartlin J, Gibney MJ. The effects of fasting and refeeding healthy volunteers on serum folate levels. Int J Vitam Nutr Res. 1998;68:142-5. 
12. Bertran N, Camps J, Fernandez-Ballart J, Arija V, Ferre N, Tous M, Simo $D$, Murphy MM, Vilella $E$, Joven J. Diet and lifestyle are associated with serum $C$-reactive protein concentrations in a population-based study. $\mathrm{J}$ Lab Clin Med. 2005;145:41-6. 